\title{
A RELAÇÃO ENTRE DESAPRENDIZAGEM E O DESENVOLVIMENTO DE COMPETÊNCIAS INDIVIDUAIS NA IMPLANTAÇÃO DE UM SISTEMA DE GESTÃO DA QUALIDADE
}

\section{THE RELATIONSHIP BETWEEN UNLEARNING AND THE DEVELOPMENT OF INDIVIDUAL COMPETENCIES DURING THE IMPLEMENTATION OF A QUALITY MANAGEMENT SYSTEM}

Henrique Geraldo Rodrigues Faculdade de Gestão e Negócios da Universidade Federal de Uberlândia - MG Universidade Presbiteriana Mackenzie - SP hgrodrigues@hotmail.com

Janette Brustein PPGA da Universidade Presbiteriana Mackenzie - SP

Janette9@uol.com.br

Submissão: $21 / 07 / 2015$

Aprovação: 22/09/2016 


\section{RESUMO}

Apesar da crescente atenção que o conceito de desaprendizagem tem recebido nos estudos em administração e organizações, há poucas evidências empíricas sobre a relação entre este fenômeno e a aquisição de novas aprendizagens. Assim, por meio de um estudo qualitativo básico, objetivou-se analisar o desenvolvimento de novas competências individuais por um grupo de supervisores de uma organização industrial, a partir de um evento catalisador da desaprendizagem, qual seja a implantação de um sistema de gestão da qualidade. Os resultados mostram que a situação de desaprendizagem propiciou a criação de um contexto favorável à adoção de uma postura crítica e de questionamento por parte dos sujeitos, levando-os a novas formulações sobre o significado do trabalho executado e, assim, ao desenvolvimento e emprego de novos atributos de competência. Os resultados implicam o entendimento de que a desaprendizagem individual mostra-se como um elemento facilitador da adoção de uma atitude de reflexão e da alteração de compreensões previamente assimiladas, ao contrário das abordagens que a concebem como um processo de abandono ou esquecimento de aprendizados. Assim, o fenômeno ganha sentido não como o oposto da aprendizagem, mas como um elemento integrado à relação dinâmica existente entre a aprendizagem e a aquisição de novas competências, especialmente nas situações em que há baixa prontidão das pessoas para a aquisição de novos aprendizados.

Palavras-chave: desenvolvimento de competências individuais, desaprendizagem, sistema de gestão da qualidade. 


\begin{abstract}
Despite the increasing attention given to the concept of unlearning in the organizational studies field, there are little empirical evidences on the procedural relationship between unlearning and the learning process. Thus, through the use of a basic qualitative study carried out in a Brazilian industry, an analysis was made of new individual competencies obtained from the unlearning situation found within the organization. The results show that the unlearning condition represented by the implementation of a quality management system led to the creation of an environment conducive to the adoption of a reflexive posture on the part of the subjects. This helped lead them to new formulations concerning the meaning of work performed and thus, the development and employment of new competence characteristics. The results imply the understanding that the individual unlearning shows up more as the adoption of a reflective attitude and less as a process of abandonment or the discarding of learning and thus unlearning attains the sense, not as the opposite of learning, but the integrated existing procedural relationship between learning and the acquisition of new competencies, especially in situations where there is low willingness of individuals to new learning.
\end{abstract}

Key-words: individual competencies development, unlearning, quality system management. 


\section{Introdução}

Estudos recentes em administração e organizações têm disseminado o conceito de desaprendizagem, com base na premissa de que aprendizados prévios têm potencial para obstruir a aquisição de aprendizados novos pelos indivíduos, o que, por sua vez, pode levar à baixa efetividade de processos de aprendizagem, mudança e inovação nas organizações (BECKER，2005，2010; CEGARRA-NAVARRO; ELDRIDGE; WENSLEY， 2014; CEPEDA-CARRIÓN; CEGARRA-NAVARRO; CARO; ELDRIDGE，2011; HISLOP; BOSLEY; COOMBS; HOLLAND, 2014). Por isso, assevera-se que, antes de buscar novas aprendizagens ou iniciar ações nelas baseadas, as pessoas precisam identificar o que é necessário desaprender, ou seja, que conhecimentos, comportamentos, crenças ou valores devem ser abandonados ou esquecidos, por não se mostrarem mais úteis ao contexto em que se encontram inseridas.

Não obstante, a maior parte das discussões sobre o tema não se baseaiam em resultados de pesquisas empíricas, o que contribui para a intensificação da ambiguidade conceitual em relação ao desenvolvimento teórico do conceito e a sua compreensão no contexto das organizações (AKGÜN; BYRNE; LYNN; KESKIN, 2007; BROOK; PEDLER; ABBOTT; BURGOYNE, 2016; MARTIN DE HOLAN; PHILLIPS, 2011). Nota-se que a relação entre a desaprendizagem e o processo de aquisição de novos aprendizados é, igualmente, pouco evidenciada, bem como objeto de divergência entre os autores que se dedicaram a tal análise. Para alguns, a desaprendizagem e a subsequente aquisição de novos aprendizados são consideradas etapas de um processo de desaprendizagem (CEPEDACARRIÓN et al., 2011; MACDONALD, 2002; NAVARRO; RODRIGO-MOYA, 2004), ao passo que para outros autores, a desaprendizagem e aprendizagem são processos distintos que podem ocorrer ou não de modo inter-relacionado (BECKER, 2005, 2010; BECKER; HYLAND; ACUTT, 2006; RUSHMER; DAVIES, 2004; TSANG; ZAHRA，2008). Há, ainda, os que argumentam que a desaprendizagem deva ser tomada como uma forma de aprendizagem em si (HISLOP et al., 2014).

Tendo em vista o entendimento segundo o qual os conteúdos adquiridos durante a aprendizagem, muitas vezes, são de difícil identificação, pois não se restringem apenas à aquisição de informação (LEFRANÇOIS, 2013), pondera-se que esta experiência deve levar a algum tipo de mudança no comportamento, resultante da articulação de um conjunto de processos e elementos relativos ao indivíduo e ao ambiente (ILLERIS, 2009). Nessa linha, 
julga-se que a identificação das competências desenvolvidas, ou seja, dos novos saberes e capacidades mobilizados, pelas pessoas, em seus contextos de ação (LE BOTERF, 2003), evidencia tanto o processo de aprendizagem, quanto os seus resultados, razão pela qual, neste estudo, tomou-se a noção de competência como parâmetro de análise do fenômeno da desaprendizagem e de suas implicações para a aquisição de novos aprendizados.

Ainda que sejam reconhecidas diferentes perspectivas para a prática e investigação do tema (LE DEIST; WINTERTON, 2005), abordagens recentes partilham da compreensão de que a competência individual relaciona-se menos a um conjunto de atributos de conhecimentos, habilidades e atitudes aplicados no trabalho executado, e mais ao contexto de ação da pessoa, em que pesam o entendimento que se tem sobre a situação de trabalho (LE BOTERF, 2003; ZARIFIAN, 2001) e a compreensão gerada sobre o trabalho feito (SANDBERG; DALL’ALBA, 2006).

Conforme demonstram Sandberg e Dall'Alba (2006), ao invés de representar um processo de completa transformação da compreensão que o indivíduo tem de seu trabalho, o desenvolvimento das competências individuais dá-se por meio de um contínuo refinamento da forma pela qual o trabalho é compreendido. A cada novo contato com o trabalho executado, as compreensões sobre este são formuladas em sentidos similares ao contato anterior, levando à reprodução das competências, ao mesmo tempo em que são refinadas. Isso resulta em que o desenvolvimento de competências não diz respeito à simples adição - ou subtração - de novos atributos de conhecimentos ou habilidades. Ao contrário, a competência é desenvolvida em meio à interação dialética e recursiva entre a pessoa e o significado que trabalho assume para ela, em sua experienciação (SANDBERG, 2000).

Compreende-se, nesse sentido, que a visão de desenvolvimento de competências como um processo cíclico representa um contraponto às abordagens que sugerem que a desaprendizagem trata-se de um fenômeno linear, pelo qual o processo de aquisição de novos aprendizados ocorre não pela ressignificação de conteúdos anteriormente aprendidos, mas pelo abandono deliberado ou esquecimento intencional desses conteúdos (CEPEDACARRIÓN et al., 2011; HISLOP et al., 2014; TSANG; ZAHRA, 2008). Este entendimento fundamenta o questionamento feito nesta pesquisa, em relação a como o desenvolvimento de novas competências individuais relaciona-se com a desaprendizagem.

Logo, o objetivo neste trabalho foi analisar o desenvolvimento de novas competências individuais por um grupo de supervisores de uma organização industrial, a partir de um 
evento catalisador da desaprendizagem, qual seja a implantação de um sistema de gestão da qualidade (SGQ). Dado este propósito, assumiu-se o entendimento de Hislop et al. (2014), segundo os quais a desaprendizagem individual é catalisada por eventos de mudança que afetam a organização ou experiências individuais relacionadas à prática do trabalho, que levam a pessoa a abandonar algum aprendizado já adquirido.

$\mathrm{Na}$ sequência, no referencial teórico, faz-se a discussão quanto às abordagens racionalistas e interpretativas de competências, e sobre a desaprendizagem individual. Posteriormente, após a fundamentação metodológica, são apresentados e discutidos os resultados, por meio de dois blocos de análise e discussão: a) as mudanças provocadas pela implantação do SGQ e a desaprendizagem dos supervisores, e b) o desenvolvimento de novas competências pelos supervisores e a sua relação com a desaprendizagem. Por fim, são tecidas as considerações finais.

\section{Referencial teórico}

\subsection{Competências individuais}

Ao se buscar compreender as bases epistemológicas constitutivas dos estudos em competência humana nas organizações, identifica-se a coexistência de diferentes enfoques teóricos. Para Sandberg (2000), os estudos em competência podem ser agrupados em torno de duas perspectivas, as racionalistas e as interpretativas, ao passo que, para Le Deist e Winterton (2005), há três abordagens dominantes, quais sejam a comportamental, a funcional e a multidimensional/holística.

Ainda que os autores recorram a modos diversos para classificar as orientações epistemológicas encontradas nesse campo, observa-se uma clara correspondência entre as duas classificações: as abordagens comportamental e funcional consideram a competência sob uma perspectiva racionalista, e a multidimensional/holística adota uma perspectiva interpretativa. Por isso, na discussão que se segue, sobre os diferentes enfoques teóricos para a competência individual, foram levadas em conta duas abordagens, as racionalistas (ou funcionalistas) e as interpretativas. 


\subsubsection{Abordagens racionalistas de competência}

As contribuições seminais à constituição do conceito de competência humana deramse em meio às investigações da psicologia comportamental, o que foi determinante para a formação das abordagens racionalistas de competência. Em seus estudos sobre a motivação, White (1959) julgava que o desempenho superior fosse determinado pelos traços de personalidade e, por isso, a capacidade de uma pessoa de interagir efetivamente com o ambiente era vista como a medida de sua competência. Com isso, as investigações subsequentes sobre competência tendiam a enfatizar a sua relação com o desempenho individual.

McClelland (1973), em especial, buscou diferenciar a competência expressa pela pessoa no desempenho de suas tarefas dos tradicionais testes de inteligência, que, à época, eram largamente aplicados na admissão de estudantes e trabalhadores nos Estados Unidos. Dentre as contribuições trazidas pelo autor aos estudos em competência, salientam-se duas: em primeiro lugar, o comportamento e o desempenho individual devem refletir as mudanças decorrentes dos aprendizados adquiridos e, segundo, o comportamento mais eficiente não é prescrito e sim determinado pela situação.

A partir dos anos 1980, o interesse nos estudos em competência volta-se para o trabalho gerencial, favorecendo a disseminação de modelos genéricos de competências gerenciais. Tanto Boyatzis (1982), como Spencer e Spencer (1993) desenvolveram modelos que listavam competências gerenciais universais, aplicáveis a quaisquer tipos de organizações e níveis gerenciais. Tais abordagens contribuíram para difundir a noção de competência como uma característica pessoal e algo determinado pela personalidade individual, conforme explicitado na definição de Parry (1996, p. 48), para quem competência diz respeito a "um conjunto de conhecimentos, habilidades e atitudes relacionados entre si [...] que é vinculado com o desempenho, que pode ser medido segundo padrões preestabelecidos e que pode ser aperfeiçoado pelo treinamento e desenvolvimento".

Entre as abordagens consideradas funcionalistas, destacam-se, ainda, Cheetham e Chivers $(1998 ; 2000)$, que propuseram um modelo de competências integrado ao conceito de profissionalismo, que abrange aspectos da natureza da prática profissional e das profissões modernas, e volta-se à compreensão sobre como as pessoas adquirem sua competência profissional. Para os autores, a competência pode ser compreendida de modo mais abrangente se forem consideradas suas cinco dimensões inter-relacionadas, quais sejam competências 
cognitivas, funcionais, comportamentais, éticas e de valores, e de metacompetências e transcompetências. No processo de desenvolvimento da competência profissional, Cheetham e Chivers (2000) salientam o papel da reflexão sobre as ações passadas e presentes, como meio para modificar comportamentos e melhorar a competência profissional.

\subsubsection{Abordagens interpretativas de competência}

Sandberg (2000) desponta dentre os primeiros críticos às abordagens tidas como funcionalistas, ao propor uma abordagem interpretativa baseada na fenomenografia, a qual tem por foco a estrutura de significados da experiência vivenciada pelo indivíduo. Para o autor, a competência não pode ser tomada como algo dissociado da interação dinâmica entre a pessoa e o trabalho executado, ao contrário, a competência humana é “[...] constituída pelo significado que o trabalho toma para o trabalhador em sua experienciação do mesmo" (SANDBERG, 2000, p. 11).

Por isso, a competência é considerada como dependente do contexto, o que denota que os atributos de competência, efetivamente, usados são determinados pelas formas pelas quais as pessoas experienciam a execução da própria atividade. Conforme complementam Sandberg e Dall'Alba (2006), é a compreensão que o indivíduo tem do trabalho que executa que determinará os atributos específicos - como conhecimentos, habilidades e atitudes - que serão desenvolvidos e empregados na execução das atividades.

Nesse sentido, para aprimorar uma competência ou desenvolver novas, é preciso que mudanças ocorram na maneira pela qual a pessoa concebe o trabalho que realiza, por meio de um processo cíclico, em que a concepção atual acerca do trabalho é tomada como um préentendimento que, quando revisado, leva a novas concepções a partir das quais a competência será desenvolvida (SANDBERG; DALL'ALBA, 2006). Por isso, a importância da atitude reflexiva ganha relevância, na medida em que colabora para ampliar consciência do indivíduo quanto ao esquema de referências e entendimentos em que suas competências se sustentam.

Para os autores, a reflexão sobre o modo pelo qual o trabalho é executado torna-se possível, somente, quando o trabalho executado é interrompido, voluntária ou involuntariamente. A reflexão voluntária ganha lugar pela ação da própria pessoa de buscar entender ou promover melhorias na execução do trabalho. A involuntária, por sua vez, é, normalmente, provocada por interrupções que independem da vontade da pessoa e que impedem a execução das atividades de um modo adequado. 
Zarifian (2001), em outra abordagem também considerada interpretativa, pondera que as mutações ocorridas no mundo do trabalho e consolidadas nos anos 1990, trouxeram a necessidade de se tomar a ação do indivíduo nas organizações não pelo prescrito nas descrições de suas tarefas, mas por sua capacidade de agir de modo competente perante situações imprevistas. A visão de competência proposta pelo autor envolve três dimensões. Primeiro, a competência é concebida como "[...] $o$ 'tomar iniciativa' $e$ 'o assumir responsabilidade' do indivíduo diante de situações profissionais com as quais se depara" (ZARIFIAN, 2001, p. 68, grifos do autor), pelo o que se pretende assinalar que, em decorrência de eventos singulares, a pessoa age além do prescrito, criando uma resposta por meio da mobilização dos conhecimentos preexistentes. Contudo, como as situações de evento não comportam a prescrição de comportamentos, a pessoa assume a responsabilidade tanto pelas iniciativas que toma, quanto por seus efeitos.

Segundo, "a competência é um entendimento prático de situações que se apoia em conhecimentos adquiridos e os transforma na medida em que aumenta a diversidade das situações" (ZARIFIAN, 2001, p. 72, grifos do autor). Isso quer dizer que, ao avaliar uma situação, o entendimento da pessoa deve estar orientado para a ação, seus componentes e efeitos, com base nos conhecimentos prévios que possui. No entanto a singularidade e a diversidade das situações demandam a mobilização de esquemas de conhecimento e ação de maneira reflexiva, o que leva à transformação desses esquemas por meio dos novos aprendizados.

Por último, "a competência é a faculdade de mobilizar redes de atores em torno das mesmas situações, é a faculdade de fazer com que esses atores compartilhem as implicações de suas ações, é fazêe-los assumir áreas de co-responsabilidade" (ZARIFIAN, 2001, p. 74, grifos do autor). Nesse sentido, situações complexas, muitas vezes, vão além do repertório de conhecimentos da pessoa, instando-a a buscar as competências que lhe faltam em sua rede social, tornando coletiva a intervenção nas situações de trabalho e propiciando o compartilhamento dos resultados da ação.

Como se observa, tanto para Sandberg (2000) e Sandberg e Dall'Alba (2006), quanto para Zarifian (2001), a discussão sobre o desenvolvimento de competências deve levar em conta o contexto de ação do indivíduo, e a sua predisposição e capacidade para a reflexão sobre o ambiente e as atividades que realiza. Le Boterf (2003), por sua vez, ao basear-se na noção de complexidade da situação de trabalho, considera que a competência do indivíduo é 
definida pelo saber administrar uma situação profissional complexa, ação pela qual são acionados os saberes necessários à adequada mobilização de recursos pessoais e do meio em que o profissional encontra-se inserido.

Para Le Boterf (2003), uma situação profissional é constituída pelo conjunto de missões, funções e tarefas que o sujeito deve assegurar na execução das funções inerentes ao seu papel profissional, bem como na relação com os outros atores e com a organização em sua totalidade. Como um "posto em evolução", que se modifica mediante a influência de fatores como os tecnológicos, econômicos e organizacionais, a complexidade de uma situação profissional é dada pela emergência do imprevisto e do circunstancial, pela coexistência de lógicas de gestão diversas e, por vezes, contraditórias, e pela instabilidade permanente das fronteiras da situação que deve ser assegurada pelo profissional (LE BOTERF, 2003).

Se, por um lado, o nível de complexidade é algo que se impõe ao indivíduo, por outro, o grau de dificuldade da situação está relacionado com a capacidade da pessoa para enfrentála, ou seja, com a prontidão da pessoa para o acionamento dos saberes necessários à adequada mobilização dos recursos de que dispõe. Pela ideia de dificuldade adotada por Le Boterf (2003), os outros elementos que compõem sua noção de competência ganham mais sentido. Os recursos que podem ser mobilizados na administração de uma situação profissional complexa são de dois tipos: os recursos pessoais, relativos a saberes, saber-fazer, aptidões e experiências acumuladas pelo indivíduo, e os recursos do meio, representados por redes relacionais, informações, equipamentos e instalações.

Contudo, para a adoção de um comportamento competente, é preciso, ainda, a capacidade de mobilizar os recursos em ações adequadas à situação, para o que Le Boterf (2003) elenca os diferentes saberes que são integrados em uma ação competente: o saber agir e reagir com pertinência, o saber combinar recursos e mobilizá-los em um contexto, o saber transpor (conceitos e aprendizados); o saber aprender e aprender a aprender, e o saber envolver-se (consigo, com o outro e com situações). É importante salientar que, na abordagem proposta pelo autor, há uma clara distinção entre os recursos necessários à ação competente e a mobilização de tais recursos em um determinado contexto, no sentido de que os recursos, apenas, potencializam a competência, ao passo que a mobilização dos recursos é o que caracteriza a competência em ação ou o comportamento competente.

Com base no exposto, neste trabalho foram adotadas as visões interpretativas de competência, pois, como sugere Velde (1999), é preciso não somente focar a aquisição de 
novas competências, mas, essencialmente, compreender o impacto de diferentes concepções de competência sobre o aprendizado.

\subsection{Desaprendizagem individual}

O conceito seminal de desaprendizagem é encontrado na teoria da interferência, uma das teorias clássicas da psicologia experimental que buscaram explicar o fenômeno do esquecimento humano (POSTMAN; UNDERWOOD, 1973). Para a teoria da interferência, o acúmulo de experiências, com o decorrer do tempo, leva à formação de memórias similares, as quais podem interferir umas nas outras durante a tentativa de recuperação de uma memória específica (BADDELEY; EYSENCK; ANDERSON, 2011). Assim, no processo de recuperação de memória considera-se que pode ocorrer tanto a interferência retroativa, em que informações adquiridas recentemente dificultam a recuperação de outras mais antigas, como a interferência proativa, em que memórias antigas obstruem o acesso a informações, recentemente, adquiridas.

Além da competição de respostas como explicação para o esquecimento, Melton e Irwin (19401 apud POSTMAN; UNDERWOOD, 1973) consideram haver um enfraquecimento da relação original entre o estímulo usado para acessar determinada memória e a resposta representada por tal memória, em decorrência de uma inibição retroativa provocada por aprendizagens posteriores e similares aos conteúdos anteriormente aprendidos e registrados na memória. Como resultado deste processo, a que os autores chamam de desaprendizagem, respostas previamente aprendidas têm sua disponibilidade reduzida, pelo efeito de obstrução decorrente de aprendizados similares e mais recentes.

No campo dos estudos em organizações, foi por meio do trabalho de Hedberg (1981) que ocorreu a apropriação da noção de desaprendizagem como a redução da disponbilidade de respostas anteriormente aprendidas pelo indivíduo. O autor enfatiza que, nas organizações, não raro, o conhecimento adquirido torna-se obsoleto, em decorrência do que é preciso que as pessoas o descartem, como forma de criar condições favoráveis para a aquisição de novas respostas e mapas mentais. Essa ação de decarte de antigos aprendizados pelas pessoas é conceituada, por Hedberg (1981), de desaprendizagem.

Entre os estudos sobre a desaprendizagem individual, destaca-se o de Becker (2005), por ser um dos primeiros a oferecer uma definição claramente delimitada para o fenômeno. A autora entende que a desaprendizagem trata-se do "[...] processo pelo qual indivíduos e 
organizações reconhecem e se libertam de aprendizados prévios (incluindo pressupostos e modelos mentais) de forma a acomodar novas informações e comportamentos" (BECKER, 2005, p. 661). Ante a premissa segundo a qual a aquisição de novos aprendizados pode ser obstruída por compreensões prévias, o efeito esperado com a desaprendizagem é o de facilitar o desenvolvimento de novas aprendizagens, mediante a renúncia à prática de conteúdos anteriormente apreendidos e que se mostram conflitantes com a mudança em curso na organização (BECKER, 2010).

Por outro lado, para Tsang e Zahra (2008, p. 1444), a desaprendizagem em seu nível individual "[...] refere-se à situação em que a pessoa torna-se consciente de que determinados elementos de conhecimento que ela possui não são mais válidos ou úteis", em razão de mudanças nas rotinas de trabalho por ela executadas. Isto representa que, para os autores, a desaprendizagem ocorre quando, após a eliminação de uma rotina de trabalho, a pessoa interrompe a execução da mesma. No entanto, dado que nem sempre as rotinas ou procedimentos de trabalho eliminados dão lugar a novos, mais do que facilitar a aquisição de novos aprendizados, a finalidade considerada para a desaprendizagem é a de levar as pessoas a ajustar seu modo de agir às mudanças promovidas na organização (TSANG; ZAHRA, 2008).

Em outra abordagem, Cepeda-Carrión et al. (2011, p. 611) tomam a desaprendizagem individual como a "arte do esquecimento", por meio da qual as pessoas, na organização, “[...] têm facilidade para abandonar ou esquecer antigos hábitos, crenças, conhecimentos e estruturas de conhecimento e substituí-los por novos [...]". Para os autores, a desaprendizagem e a aquisição de novos aprendizados são fenômenos inter-relacionados e elementos centrais do que definem como contexto de desaprendizagem, ou seja, a dinâmica organizacional que facilita o abandono de antigos hábitos, crenças e conhecimentos, e a sua substituição por novos, com o propósito de favorecer a reorientação do modelo de gestão adotado e de pressupostos que orientam o comportamento dos membros da organização.

Por último, encontram-se Hislop et al. (2014, p. 549), que concebem a desaprendizagem individual como uma forma especial de aprendizagem, a qual "[...] envolve um processo consciente de escolher abrir mão, abandonar ou parar de usar conhecimento, valores ou comportamentos". Na visão dos autores, trata-se de uma aprendizagem pelo fato de que, para desaprender, é preciso que a pessoa adquira conhecimentos que a ajudem a reconhecer que é preciso abandonar algum aprendizado antigo. Ainda, a desaprendizagem não 
representa a extinção ou perda de aprendizados prévios, pois, ao parar de usar um antigo aprendizado de forma deliberada, a pessoa, também, poderá acionar tal conhecimento e aplicá-lo em outras situações.

Para Hislop et al. (2014), há dois tipos de desaprendizagem individual. No caso da desaprendizagem comportamental, a pessoa interrompe a execução de práticas, atividades ou rotinas, a qual tem pouco impacto sobre os pressupostos e valores pessoais. Já em relação à desaprendizagem cognitiva, ocorre o abandono de conteúdos arraigados, como valores e pressupostos. Ambas as formas de desaprendizagem podem ser estimuladas e moldadas por eventos de mudança (como um novo regulamento que altera uma rotina de trabalho desenvolvida pela pessoa), bem como por experiências pessoais (como a mudança na forma de liderar em razão de uma experiência negativa com o grupo de trabalho).

Nota-se que a importância atribuída à desaprendizagem decorre, principalmente, das considerações em relação ao seu potencial para orientar a mudança de comportamento ou a adequação dos modos de pensar de agir a novas premissas instituídas no ambiente organizacional. Alguns estudos teórico-empíricos indicam que a desaprendizagem, promovida previamente ou de modo concomitante às mudanças, favoreceu a aquisição de novos aprendizados pelas pessoas, em situações como as de treinamento e desenvolvimento (BECKER; HYLAND; ACUTT, 2006), implementação de novas tecnologias na organização (CEPEDA-CARRION et al., 2011) e reformulação de rotinas de trabalho (LEE, 2011).

No entanto, os resultados de tais investigações não evidenciam a dinâmica processual pela qual os fenômenos da desaprendizagem e da aprendizagem ocorreram. No que tange à relação esperada entre a desaprendizagem e o desenvolvimento de competências, salienta-se que não se identificam investigações publicadas, no campo de estudos da administração e organizações, que se dedicaram a tal objeto, conforme busca por trabalhos científicos realizada junto às bases de dados Portal de Periódicos da Capes, EBSCO (Bussiness Source Complete) e ProQuest, em julho de 2016.

Com base no exposto, avalia-se que a desaprendizagem - vista como um elemento facilitador da modificação do modo de pensar e de agir - contribui para o aprimoramento e o desenvolvimento de novas competências na medida em que fomenta a conscientização, pelo indivíduo, quanto à necessidade de interromper a maneira habitual de comportar-se. Sabe-se que nem sempre os processos de aprendizagem levam aos efeitos esperados em termos de mudança de comportamento, em consequência, entre outros fatores, da dificuldade que as 
pessoas podem enfrentar para deixar de usar aprendizados prévios e romper com antigos hábitos que, apesar de terem sido eficazes no passado, não se mostram adequados ou úteis à situação presente (ILLERIS, 2009; LONGENECKER; NEUBERT; FINK, 2007).

Para a adoção de tal perspectiva, contudo, leva-se em conta que a mudança de comportamento representada pela desaprendizagem diz respeito não ao abandono deliberado ou esquecimento intencional de aprendizados já adquiridos, como sugerido em algumas abordagens (CEPEDA-CARRIÓN et al., 2011; HISLOP et al, 2014), mas ao entendimento de que as compreensões prévias não se mostram como respostas pertinentes às demandas contextuais prevalentes. Nesse sentido, faz-se necessária a aquisição de novos saberes, mediante o contínuo refinamento das competências individuais, em consonância com a compreensão que a própria pessoa possui do trabalho que executa (SANDBERG, 2000; SANDBERG; DALL'ALBA, 2006).

Com esta exposição, objetivou-se, especialmente, expor as diferentes concepções sobre a desaprendizagem em seu nível individual, como forma de evidenciar, também, a ambiguidade em relação à definição do conceito. Ainda que a definição conceitual inicialmente adotada, neste trabalho, tenha sido a de que a desaprendizagem diz respeito à tomada de consciência quanto à necessidade de parar de usar algo aprendido anteriormente, em consonância com Hislop et al. (2014), na discussão dos resultados foram consideradas as demais abordagens, inclusive, como forma de explorar as interpretações diversas formuladas pelos sujeitos.

\section{Aspectos metodológicos}

$\mathrm{O}$ presente trabalho, de natureza qualitativa, baseia-se no paradigma interpretativista e numa ontologia ancorada no entendimento de que as realidades são múltiplas e socialmente construídas, dado que se objetivou apreender os significados atribuídos pelos sujeitos a uma situação experienciada (GUBA; LINCOLN, 1994; GEPHART, 1999). Adotou-se a proposta do estudo qualitativo básico como orientador da estratégia de pesquisa, o qual se caracteriza, primariamente, pelo foco no desvelamento e interpretação de significados atribuídos pelas pessoas na construção da realidade social (MERRIAM, 2002).

$\mathrm{O}$ estudo foi realizado em uma empresa fabricante de moldes e equipamentos para produção de embalagens de vidro, que agrega 260 empregados e é uma das três indústrias brasileiras em seu segmento. Seu faturamento, em 2013, foi de R 40 milhões. A escolha de 
tal empresa deu-se em função desta ter conduzido, entre os anos de 2012 e 2014, a implantação de um SGQ em seu departamento industrial, o que se mostrou adequado para o propósito da pesquisa de compreender as competências desenvolvidas a partir de uma situação em que se fizesse necessária alguma forma de desaprendizagem pelos envolvidos.

Para o levantamento dos dados, realizado em abril de 2014, lançou-se mão da entrevista qualitativa individual, pois se buscou flexibilidade na ordenação e formulação das questões durante a interação entrevistador e entrevistado (BRYMAN, 2004). Primeiro, para compreender o processo de implantação do SGQ e a sua finalidade, foram entrevistados o gerente geral da empresa e a gestora do SGQ, os quais foram os idealizadores e coordenadores da implantação do SGQ no departamento industrial da empresa. O roteiro de entrevista aplicado continha questões relativas ao histórico, objetivos, dificuldades enfrentadas e resultados alcançados com a implantação do SGQ.

Posteriormente, para identificar as competências desenvolvidas, a partir da situação de desaprendizagem representada pela implantação do SGQ, foram entrevistados oito supervisores dos diversos setores operacionais do departamento industrial, responsáveis pela implantação das ações do SGQ em suas próprias áreas de trabalho. Do roteiro de entrevista aplicado junto aos supervisores constavam questões relativas à experiência de implantação do SGQ, às mudanças no trabalho provocadas pelo SGQ, às novas competências desenvolvidas e ao que foi preciso desaprender. $\mathrm{O}$ uso de roteiros de entrevista distintos teve por finalidade possibilitar o contraste da visão dos coordenadores da implantação do SGQ com a dos supervisores dos setores de trabalho, quanto aos resultados esperados com o novo sistema e as mudanças efetivamente ocorridas no trabalho.

Para o tratamento dos dados, foi utilizada a técnica da análise de conteúdo, com o propósito de se reconstruir o conhecimento expresso pelos sujeitos mediante a análise das transcrições das entrevistas (BAUER, 2002). Por meio da identificação das unidades de significado, bem como de suas relações, as seguintes categorias ou dimensões emergiram dos dados: o processo de implantação do SGQ, as mudanças no trabalho provocadas pela implantação do SGQ, a desaprendizagem dos supervisores e as novas competências desenvolvidas pelos supervisores. Na discussão dos resultados, tais dimensões foram organizadas em dois blocos: a) as mudanças provocadas pela implantação do SGQ e a desaprendizagem dos supervisores, e b) o desenvolvimento de novas competências pelos supervisores e a sua relação com a desaprendizagem. 


\section{Apresentação e discussão dos resultados}

\subsection{As mudanças provocadas pela implantação do SGQ e a desaprendizagem dos supervisores}

Nesta pesquisa, a relação entre o desenvolvimento de novas competências e a desaprendizagem foi analisada no contexto da implantação de um SGQ no departamento industrial da empresa, com vistas à obtenção da certificação ISO 9001:2008 (International Organization for Standardization) para o seu sistema produtivo. Conforme indica a gestora do SGQ, a necessidade de melhoria do desempenho da empresa, junto ao cliente, representou um dos principais fatores motivadores para a busca por esse tipo de certificação:

A nossa primeira pesquisa de satisfação do cliente, que nós soltamos... nossa! Foi um horror! Dentre elas, a pior, a gente teve muita reclamação referente ao prazo de entrega, a nossa principal reclamação. E a segunda, foi a parte de comunicação, pouco contato com o cliente. (Gestora do SGQ)

Com a implantação do SGQ, esperava-se mudar o comportamento das pessoas em relação à forma de execução das tarefas, fazendo com que elas adotassem procedimentos racionalizados e adequados aos princípios de gerenciamento de rotinas, como a documentação dos procedimentos de trabalho, a formalização das comunicações e decisões, a implantação de controles operacionais e o acompanhamento do cumprimento dos indicadores de qualidade. Do ponto de vista estratégico, além de possibilitar a retenção do conhecimento acumulado pelos empregados, a implantação do SGQ representou o caminho, adotado pela empresa, para atender à imposição de tornar-se mais competitiva e abrir novos mercados, como expressa o gerente industrial:

Uma vez padronizado um sistema de gestão da qualidade, que é o que nós estamos buscando, aí a gente quer provocar outras mudanças, inclusive para o mercado. $\mathrm{O}$ mercado, hoje, demanda o que para você ser um bom fornecedor homologado? Ter o sistema ISO, porque não tem como fugir dessa ISO. Então, para nós, é isso que está gerando em termos de expectativa e, depois, a grande mudança. Sendo ISO, vai abrir muitas portas do mercado para nós. (Gerente industrial)

Todos os membros das equipes setoriais do departamento industrial da empresa foram envolvidos na implantação do SGQ, por meio da participação em palestras de disseminação de informações, treinamentos, reuniões de revisão dos processos e tarefas de elaboração da documentação dos processos. Mediante o acompanhamento técnico da gestora do SGQ, os supervisores dos setores atuaram como facilitadores da implantação do SGQ, sendo 
responsáveis pelo envolvimento das respectivas equipes e coordenação da execução das atividades de racionalização e padronização dos processos de trabalho de suas áreas.

Nessa perspectiva, para os supervisores, os efeitos da implantação do SGQ sobre o próprio trabalho mostraram-se, especialmente, na mudança da maneira de desenvolver as rotinas de trabalho, mediante a necessidade de atender aos princípios de padronização, documentação, controle e eficiência dos processos de trabalho. Os excertos de alguns dos relatos ilustram este aspecto:

O que mais impactou, positivamente, no nosso trabalho, no departamento em si, foi a parte de organização. Hoje, a gente está conseguindo ser mais organizado e, de certa forma, começa a apresentar certa eficiência em resgatar dados históricos, ali, aqui, tal documento. (Supervisor 1)

Agora eu tenho que deixar tudo mais parametrizado. Arquivamento de pedidos, controle de indicadores, eram coisas que a gente não fazia e que a gente começou a fazer [...]. (Supervisor 5)

Devido à ênfase sobre a formalização dos procedimentos empregados no trabalho, foram estabelecidas novas formas de comunicação, dentro das equipes e entre os diversos setores do departamento industrial, com a finalidade de documentar respostas e trocas de informações, como indica um dos supervisores:

A gente passou a cobrar um pouco mais, passou a ser mais cobrado e passou a ter mais registro de informação. E parou de ter muita coisa informal, principalmente, aquilo da pessoa parar o outro no corredor e falar 'Eu preciso disso, disso e daquilo outro', sendo que não tinha documento, nenhum registro. Depois, de repente, a pessoa vinha e dizia 'Você não me entregou o pedido, você não fez isso, não fez aquilo', sendo que você tinha feito. (Supervisor 3)

As mudanças no ambiente de trabalho, também, foram descritas na forma de maior preocupação, por parte dos supervisores e dos demais membros das equipes, com qualidade do produto final e com a adoção de procedimentos voltados à obtenção deste padrão de qualidade:

A implantação está nos ajudando a aceitar essa ideia [de] que é preciso fazer as mudanças que estão sendo feitas, para a gente conseguir o padrão de qualidade que queremos para os produtos. Trouxe essa consciência de que é preciso melhoria de processo. (Supervisora 6)

Pelos relatos, observa-se que o conteúdo das mudanças consideradas pelos supervisores vai ao encontro do teor da proposta de implantação do SGQ de induzir a elevação da qualidade do serviço prestado ao cliente, mediante a adoção, pelas pessoas, de procedimentos de trabalho e comportamentos consonantes com os requisitos de um sistema de gerenciamento da qualidade. Ainda, é interessante notar que, na visão dos supervisores, a busca pelo atendimento às novas premissas de trabalho significou, além das mudanças de 
cunho procedimental, a imputação de maior responsabilidade individual pelos resultados do trabalho desenvolvido, aspecto salientado por um dos sujeitos:

Houve um pouco mais de responsabilidade com relatórios, com gráfico para apresentar em reuniões, essas tarefas. Houve um pouco mais de tarefa, mais responsabilidade. Não que nós não tínhamos de entregar a peça correta. Mas, aí, tinha peça que a gente não se preocupava: 'Não, isso aí não tem problema, isso daí é uma medida fracionária' [referindo-se a uma medida superior ao especificado]. (Supervisor 4)

Entende-se que este efeito sinaliza as novas interpretações, sobre o trabalho, formuladas pelos supervisores, em que a conscientização de que os resultados do trabalho devem provocar um efeito positivo sobre os clientes mostra-se, fortemente, presente, em consonância com a noção de serviço proposta por Zarifian (2001). De modo diverso, no entanto, um dos gestores indica que o seu trabalho ganhou a conotação de uma atividade burocrática e com reduzidas possibilidades de ação fora do conteúdo prescrito nos manuais de procedimentos, então, adotados na empresa:

Com esse tipo de implantação, não é só coisas que vêm para agregar valor, algumas coisas também foram tiradas. Quando você coloca, por exemplo, uma parte de controle de qualidade, você engessa um pouco o setor também. Você cria uma planilha que você tem que fazer anotações, um mapeamento, você vai engessando, de certa forma. (Supervisor 8)

Por isso, para adaptar-se ao novo contexto de trabalho, os supervisores foram instados, não apenas, a incorporar novas rotinas e procedimentos ao escopo de suas atividades, mas, igualmente, a modificar o modo habitual de agir em situações diversas relativas ao trabalho, como ilustra o supervisor:

Eu tive que ter essa mudança, de seguir as normas da ISO, mesmo que nem sempre elas vão de acordo com aquilo que eu achava que precisava fazer para atender o cliente. Antes, a gente parava ou mandava um desenho para a fábrica sem uma análise prévia. Eu sei que eu não posso fazer mais isso, eu tenho que, mesmo perdendo tempo, fazer esse tipo de procedimento para se enquadrar à ISO. (Supervisor 5)

Isto quer dizer que, para lidar com as novas exigências do ambiente impostas pela implantação do SGQ, além de assimilar e praticar novas competências tidas como relevantes, os supervisores tiveram que abandonar formas antigas de lidar com as situações do contexto de trabalho, ou seja, desaprender conteúdos que foram objeto das mudanças promovidas na organização. No caso de uma das supervisoras, a desaprendizagem envolveu parar de executar rotinas de trabalho, anteriormente, estabelecidas:

[...] com a implantação da ISO, viu-se a necessidade de muitas alterações de rotina, pois elas estavam sendo revistas e racionalizadas. E, então, eu tive que deixar de lado uma ou outra rotina de projeto que eu tinha e assumir outras, com alterações, novas atribuições. (Supervisora 6) 
Este relato evidencia a desaprendizagem de rotinas sugerida por Tsang e Zahra (2008), em que a pessoa é levada a interromper a execução de suas tarefas conforme conhecimentos e pressupostos, anteriormente, válidos. Nota-se que, diferentemente das considerações de Hislop et al. (2013) de que a desaprendizagem de rotinas tem pouco impacto sobre os pressupostos pessoais, o relato feito aponta para a interpretação de que a experiência de interromper a execução de uma antiga rotina de trabalho é vista, também, como um processo de abrir mão de conteúdos arraigados. Tal representação coaduna com a perspectiva de Feldman e Pentland (2003), segundo a qual as rotinas, por serem realizadas por pessoas específicas e em contextos específicos, possuem uma dimensão performativa e, desse modo, sofrem a influência dos mapas cognitivos das pessoas que as executa.

Como sugere Becker (2010), a desaprendizagem de quaisquer conteúdos envolve reconhecer que, em contextos específicos, aprendizados preexistentes podem conflitar com a mudança em curso na organização. Nessa linha, a mesma supervisora indica que a tomada de consciência quanto à importância de parar de agir do modo habitual deu-se mediante o entendimento de que os procedimentos que vigiam não contemplavam ações voltadas à garantia da qualidade das operações de produção, umas das premissas das mudanças em implantação:

[...] mudar um método de fazer alguma coisa é mais difícil, porque você está acostumado, está até viciado, está viciado em fazer as coisas de certas maneiras. Mas, se eu continuasse a fazer da outra maneira, eu... eu estaria contra tudo aquilo que a [empresa] vem se esforçando para trazer para cá [...]. (Supervisora 6)

Em outros casos, a desaprendizagem vivenciada pelos supervisores relaciona-se a modos habituais de interpretar e reagir a situações de trabalho diversas, como a tendência a desenvolver o trabalho de modo informal, sem o devido registro das informações e geração da documentação pertinente. Para o supervisor 2, foi preciso desaprender o comportamento de aprovar peças e equipamentos que não atendiam ao padrão de qualidade necessário ao produto final:

Antigamente, a gente inspecionava peças e equipamentos, e o que acontecia? $\mathrm{O}$ equipamento estava ruim e eu acabava aprovando aquele equipamento, daquele jeito mesmo. Porque, antigamente, não tinha exigência. A peça batia lá em cima, dava um retrabalho, voltava e a gente fazia de novo, não tinha o segmento que nós temos hoje. Eu pensava: 'Mas a peça tem que subir, então vai subir errado mesmo; é melhor voltar do que a gente não mandar o equipamento'. Esses hábitos antigos. Então, hoje, foi quebrado tudo isso aí. Isso aí é hábito que não vai voltar mais e nem pode voltar para uma empresa igual a essa. (Supervisor 2 )

Como se observa, colaborou para o supervisor desaprender a constatação, feita mediante reflexão sobre as alterações que estavam ocorrendo no ambiente de trabalho, de que 
os procedimentos antigos de aprovação de peças e equipamentos geravam índices muito altos de reprovação do produto final:

Chegou um momento que eu pensei: eu faço isso aqui e se isso aqui não é viável, então, o que acontece? Vai dar problema, vai chegar lá na fábrica e eles vão devolver, porque, agora, tem o SGQ. E se eles não devolverem, o cliente vai mandar de volta aquele produto que não foi [produzido e enviado] de acordo com o que ele mandou para nós. (Supervisor 2)

Também, o supervisor 4 descreve como foi o desaprendizado da tendência a reagir de modo negativo às demandas, feitas pela gerência, por alterações na programação de produção:

Eu era muito perfeccionista, eu gostava de tudo certinho, tudo alinhadinho. E hoje, devido à flexibilidade da empresa, a prioridade aqui muda, constantemente, o serviço muda, constantemente. Às vezes, de manhã, nós estávamos fazendo um serviço e devido à urgência, à necessidade do [cliente], a programação mudava. Eu ficava muito irritado, muito nervoso e aquilo me estressava. [...] Então eu coloquei em mim o seguinte: 'Eu tenho que ser maleável, eu tenho que largar algumas atitudes que, além de ser prejudicial, eu comecei a entender a empresa'. Ela muda, constantemente, mas tem uma razão dessa mudança. (Supervisor 4)

Por meio desses relatos, observa-se tanto o que Hislop et. al (2014) definem como desaprendizagem cognitiva e que envolve abandonar ou parar de usar determinados valores ou pressupostos, quanto o apontamento de Becker (2005) de que a desaprendizagem pode envolver de aprendizados prévios na forma de pressupostos e modelos mentais. Em consonância com os mesmos autores, a desaprendizagem vivenciada pelos supervisores mostrou-se, do ponto de vista individual, um processo consciente de interromper a forma habitual de agir, seja pelo entendimento de que o modo antigo de comportar-se não se mostra adequado, seja pela intenção de adequar-se às mudanças em curso na organização.

Dado o entendimento de que o desenvolvimento de novas aprendizagens pode ser obstruído por antigos conhecimentos e comportamentos, Becker (2005; 2010), bem como Cepeda-Carrión et al. (2011), asseveram que a desaprendizagem tem por principal finalidade favorecer a aquisição de novos aprendizados, devido ao seu potencial de atenuação dos comportamentos de sobrevalorização e reforço de compreensões já adquiridas, em detrimento de novas. No caso dos supervisores desta pesquisa, a desaprendizagem, igualmente, colaborou para que novas competências individuais pudessem ser assimiladas e, efetivamente, praticadas.

\subsection{O desenvolvimento de novas competências pelos supervisores e a sua relação com a desaprendizagem}

As situações organizacionais que apresentam características distintas do habitual exigem das pessoas a mobilização de seus esquemas de conhecimento e a ação de modo 
reflexivo, o que oportuniza o desenvolvimento de novos aprendizados (ZARIFIAN, 2001).

No caso da implantação do SGQ, os supervisores foram confrontados por uma situação profissional que trouxe novos objetivos e tarefas (LE BOTERF, 2003) e, assim, instados a desenvolver novas competências:

Essa competência que eu estou achando, que está sendo mais viável, é justamente lidar com pessoas. Eu percebi que é uma coisa, totalmente, diferente da outra, porque como eu trabalho e meu setor tem várias pessoas, cada um tem um relacionamento diferente, um raciocínio diferente. Então, é coisa que eu tive que desenvolver, para entender cada uma em seu raciocínio. (Supervisor 2)

Nesse caso, verifica-se a habilidade de estabelecer interações de modo pertinente como recurso, desenvolvido pelo supervisor, para mobilizar os membros da equipe de trabalho em torno de ações compartilhadas (ZARIFIAN, 2001). Para outros supervisores, houve a aquisição da capacidade de comunicar-se melhor, que se mostra na forma de um saber envolver-se tanto com as outras pessoas, quanto com as situações (LE BOTERF, 2003):

[...] se falar com pessoas for uma competência, eu acrescentei isso, eu estou lidando melhor com pessoas. Eu tenho que aprender a falar com pessoas diferentes, com diferentes linguagens, pessoas com linguagens técnicas, pessoas que não têm tanta linguagem técnica, gestores que também não usam linguagem técnica alguma. Minha competência, que eu tive que trabalhar, foi essa: falar com pessoas diferentes, em momentos diferentes, com linguagens diferentes. (Supervisora 6)

É observado, também, o desenvolvimento de competências na forma de conhecimentos e as habilidades técnico-funcionais, relacionadas à execução das próprias atividades, bem como aos novos papéis inerentes ao SGQ. As falas dos supervisores 4 e 1 ilustram este aspecto:

Como o meu negócio é graxa na unha, vamos falar assim, chão de fábrica, você não mexia tanto com relatórios, com gráficos, com o computador. Então, eu tive que me aperfeiçoar mais, a deixar a mão um pouco mais limpa para mexer mais burocraticamente, ser mais burocrático. (Supervisor 4)

Uma das novas competências foi me tornar auditor, nós somos auditores internos da ISO. [...] ele precisa conhecer a norma, precisa saber aplicá-la na fábrica, no processo como um todo, ele precisa saber aplicar isso. (Supervisor 1)

Conforme apontam os relatos dos supervisores, o desenvolvimento de tais competências deu-se de modo independente da desaprendizagem vivenciada. No entanto, para a aquisição de outras competências, os sujeitos indicam que a desaprendizagem de modos de pensar e de agir, que não se mostravam mais adequados ao contexto organizacional, foi importante, como sugere o relato de uma das supervisoras:

Aquela antiga [rotina] você luta contra ela, mas você tem que lutar tentado jogar ela fora. Você precisa tentar absorver coisas novas, mas é uma luta você deixar de lado aquela rotina antiga. Mas, sim, você tem que usar a nova. É uma luta deixar a antiga de lado. [...] Vício. É uma luta, mas para fazer a nova rotina, sim, é esperado deixar de lado a outra. Porque também, se você ficar com duas rotinas, você não estará fazendo nem a antiga nem a nova, você estará fazendo uma terceira, que não é nem uma, nem outra. (Supervisora 6) 
Além do necessário abandono de antigas rotinas, com vistas à realização, de modo competente, de novos procedimentos de trabalho, verifica-se que a desaprendizagem mostrouse útil, também, no desenvolvimento de outros tipos de competência, como a relativa ao saber envolver-se com outras pessoas e situações (LE BOTERF, 2003), conforme evidencia a fala do supervisor 3:

\begin{abstract}
Uma coisa que eu ganhei de competência, que eu percebo que comecei a mudar, é a forma de cobrar as pessoas. Antes, por eu saber fazer, se uma pessoa demorava muito para fazer o que eu tinha pedido, eu mesmo já fazia e pronto. Não ficava esperando. [...] Para mudar isso, saber chegar nas pessoas, saber conversar e pedir para fazer uma coisa que eu já tinha falado, eu tive que parar de fazer daquele jeito que eu fazia. Eu tinha muito disso: 'Eu faço e não gosto de ficar pedindo'. Assim, às vezes, com uma certa arrogância. Então, eu creio que isso eu comecei a melhorar bastante. (Supervisor 3)
\end{abstract}

Nesse sentido, observa-se que o efeito da desaprendizagem sobre o desenvolvimento de novas competências deu-se no sentido de facilitar a mudança de concepções, atitudes e comportamentos, pois, para agir de modo competente, foi preciso, não apenas, adquirir novos aprendizados, mas interromper a prática de aprendizados antigos, avaliados como inadequados para o novo contexto de trabalho. É o caso do supervisor 7, que, tendo julgado importante desaprender o comportamento recorrente de centralizar a resolução de problemas e a tomada de decisões sobre questões concernentes ao setor que coordena, apontou, como uma das novas competências adquiridas, a capacidade de estabelecer interações pessoais de modo pertinente e mobilizar os membros da equipe de trabalho em torno de ações compartilhadas (ZARIFIAN, 2001):

Então, eu também estou aprendendo isso, aqui: nem sempre eu vou conseguir fazer tudo, nem sempre tudo vai estar na minha mão; se eu for um bom gestor, eu vou ter uma equipe boa e vou delegar essas atividades [...] parando para refletir e saber de fato mesmo: 'Será que isso é pertinente a mim ou não é? Será que eu sou o mais apto a resolver isso ou não sou?'. (Supervisor 7)

Pondera-se que, ao se mostrar como um evento que levou à interrupção do trabalho desempenhado pelos supervisores, a desaprendizagem propiciou a constituição de um ambiente favorável para a reflexão sobre a forma habitual de realização das próprias atividades, em consonância com entendimento expresso por Sandberg e Dall'Alba (2006), segundo o qual a interrupção do trabalho, de modo voluntário ou não, é necessária para que a atitude reflexiva quanto ao mesmo tome lugar. Mediante a adoção de tal postura de avaliação crítica sobre comportamentos adotados, novas interpretações sobre o trabalho executado puderam ser formuladas, o que contribuiu para a aquisição de novos aprendizados e à transformação de compreensões prévias (SANDBERG, 2000; ZARIFIAN, 2001): 
Você tem que melhorar a sua forma de passar a informação, melhorar a sua forma de chegar nas pessoas. Porque, da mesma forma como eu recebia muita coisa informal, eu passava, também, informal. Então, você começa a se policiar mais, a ter aquele cuidado de ter a certeza de que aquela informação que você está passando tem que ser entendida e compreendida pela pessoa. Porque, senão, ficava assim, a pessoa empurra para mim, eu empurro para o outro, o outro empurra para o outro. No final, sai, mas não sai da forma correta. (Supervisor 3)

Conforme esclarece Le Boterf (2003), a situação profissional torna-se complexa à medida que fatores ambientais e organizacionais diversos impactam o trabalho realizado pela pessoa, o que demanda continuamente a sua capacidade de acionar e integrar os saberes em uma ação competente. Nota-se, dessa maneira, que as novas competências desenvolvidas pelos supervisores mostram sintonia com as expectativas, apresentadas pelos gestores da empresa e do SGQ, sobre os resultados da implantação do sistema de qualidade. No Quadro 1, é feita a exposição, de modo sintético, das interpretações, formuladas pelos supervisores, quanto às mudanças em seu trabalho, à desaprendizagem vivenciada e às novas competências desenvolvidas.

Quadro 1: Interpretações, formuladas pelos supervisores, quanto às mudanças em seu trabalho, ao tipo de desaprendizagem vivenciada e às novas competências desenvolvidas

\begin{tabular}{|c|c|c|c|c|}
\hline Sujeito & $\begin{array}{c}\text { Mudanças ocorridas } \\
\text { no trabalho }\end{array}$ & $\begin{array}{c}\text { Tipo de } \\
\text { desaprendizagem } \\
\text { vivenciada }\end{array}$ & $\begin{array}{c}\text { Por que foi } \\
\text { importante } \\
\text { desaprender }\end{array}$ & $\begin{array}{c}\text { Novas competências } \\
\text { desenvolvidas }\end{array}$ \\
\hline 1 & $\begin{array}{l}\text { Maior exigência pela } \\
\text { organização do } \\
\text { trabalho, e pelo } \\
\text { registro e controle de } \\
\text { informações e } \\
\text { documentos. }\end{array}$ & $\begin{array}{l}\text { Desenvolver o } \\
\text { trabalho de modo } \\
\text { informal, sem a } \\
\text { observância de } \\
\text { princípios da gestão } \\
\text { pela qualidade. }\end{array}$ & $\begin{array}{l}\text { O modo habitual de } \\
\text { realizar o trabalho } \\
\text { gerava problemas } \\
\text { como a perda de } \\
\text { informações e o } \\
\text { extravio de } \\
\text { documentos, e o uso } \\
\text { de informações } \\
\text { desatualizadas. }\end{array}$ & $\begin{array}{l}\text { Conhecimento das } \\
\text { normas de qualidade e } \\
\text { da forma de aplicá- } \\
\text { las. } \\
\text { Cumprimento das } \\
\text { atividades de acordo } \\
\text { com os procedimentos } \\
\text { previstos. }\end{array}$ \\
\hline 2 & $\begin{array}{l}\text { Realizar o trabalho } \\
\text { conforme as normas e } \\
\text { procedimentos } \\
\text { estabelecidos pelo } \\
\text { SGQ. }\end{array}$ & $\begin{array}{l}\text { Aprovar peças e } \\
\text { equipamentos que não } \\
\text { atendiam ao padrão } \\
\text { de qualidade } \\
\text { necessário ao produto } \\
\text { final. }\end{array}$ & $\begin{array}{l}\text { Os procedimentos } \\
\text { antigos de aprovação } \\
\text { de peças e } \\
\text { equipamentos } \\
\text { geravam índices } \\
\text { muito altos de } \\
\text { reprovação do } \\
\text { produto final. }\end{array}$ & $\begin{array}{l}\text { Elaboração de } \\
\text { relatórios de controle } \\
\text { e documentação dos } \\
\text { processos de trabalho. } \\
\text { Capacidade de } \\
\text { identificar e implantar } \\
\text { melhorias nos } \\
\text { processos de trabalho. }\end{array}$ \\
\hline 3 & $\begin{array}{l}\text { Formalização da } \\
\text { comunicação entre os } \\
\text { setores e registro das } \\
\text { informações relativas } \\
\text { ao cumprimento das } \\
\text { tarefas. }\end{array}$ & $\begin{array}{l}\text { Transmitir } \\
\text { informações } \\
\text { importantes à } \\
\text { consecução do } \\
\text { processo produtivo de } \\
\text { maneira informal. } \\
\text { Centralizar a }\end{array}$ & $\begin{array}{l}\text { A informalidade do } \\
\text { processo de } \\
\text { atendimento aos } \\
\text { pedidos internos de } \\
\text { materiais e insumos } \\
\text { gerava problemas } \\
\text { como o não } \\
\text { processamento de }\end{array}$ & $\begin{array}{l}\text { Saber delegar tarefas } \\
\text { aos membros da } \\
\text { equipe e acompanhar } \\
\text { a sua execução. } \\
\text { Comunicar-se de } \\
\text { forma que a } \\
\text { informação }\end{array}$ \\
\hline
\end{tabular}




\begin{tabular}{|c|c|c|c|c|}
\hline & & $\begin{array}{l}\text { execução de tarefas } \\
\text { passíveis de ser } \\
\text { realizadas por outros } \\
\text { membros da equipe. }\end{array}$ & $\begin{array}{l}\text { pedidos e o extravio } \\
\text { de materiais e } \\
\text { informações. }\end{array}$ & $\begin{array}{l}\text { transmitida seja, } \\
\text { claramente, } \\
\text { compreendida pelas } \\
\text { outras pessoas. }\end{array}$ \\
\hline 4 & $\begin{array}{l}\text { Implantação de } \\
\text { especificações } \\
\text { técnicas para o } \\
\text { processo produtivo e } \\
\text { de relatórios de } \\
\text { avaliação. } \\
\text { Atribuição de maior } \\
\text { responsabilidade } \\
\text { pelos resultados do } \\
\text { trabalho. }\end{array}$ & $\begin{array}{l}\text { Reagir de modo } \\
\text { negativo às } \\
\text { demandas, feitas pela } \\
\text { gerência, por } \\
\text { alterações na } \\
\text { programação de } \\
\text { produção. }\end{array}$ & $\begin{array}{l}\text { Entender as razões da } \\
\text { empresa para mudar, } \\
\text { frequentemente, a } \\
\text { programação de } \\
\text { produção. }\end{array}$ & $\begin{array}{l}\text { Uso de computadores } \\
\text { e elaboração de } \\
\text { relatórios } \\
\text { informatizados. } \\
\text { Entendimento sobre a } \\
\text { necessidade, da } \\
\text { organização, de } \\
\text { alterar a programação } \\
\text { de produção. }\end{array}$ \\
\hline 5 & $\begin{array}{l}\text { Implantação de } \\
\text { controles operacionais } \\
\text { e de indicadores de } \\
\text { desempenho. } \\
\text { Aumento da carga de } \\
\text { trabalho. }\end{array}$ & $\begin{array}{l}\text { Executar as rotinas de } \\
\text { planejamento e } \\
\text { controle da produção } \\
\text { com base no modelo } \\
\text { antigo de trabalho. }\end{array}$ & $\begin{array}{l}\text { A avaliação dos } \\
\text { resultados da } \\
\text { produção era feita } \\
\text { sem levar em conta } \\
\text { dados confiáveis, pois } \\
\text { o registro de } \\
\text { informações ocorria } \\
\text { de modo aleatório, } \\
\text { sem um padrão. }\end{array}$ & $\begin{array}{l}\text { Compreensão sobre a } \\
\text { importância de } \\
\text { cumprir os novos } \\
\text { procedimentos de } \\
\text { trabalho, de acordo } \\
\text { com os princípios da } \\
\text { gestão pela qualidade. }\end{array}$ \\
\hline 6 & $\begin{array}{l}\text { Incorporação de } \\
\text { novos procedimentos } \\
\text { às rotinas de trabalho, } \\
\text { voltados à garantia da } \\
\text { qualidade do produto } \\
\text { final. } \\
\text { Ampliação das } \\
\text { atribuições inerentes } \\
\text { ao cargo ocupado. }\end{array}$ & $\begin{array}{l}\text { Realizar o trabalho } \\
\text { conforme as rotinas } \\
\text { que prevaleciam. }\end{array}$ & $\begin{array}{l}\text { Os procedimentos que } \\
\text { vigiam não } \\
\text { contemplavam ações } \\
\text { voltadas à garantia da } \\
\text { qualidade das } \\
\text { operações de } \\
\text { produção. }\end{array}$ & $\begin{array}{l}\text { Conhecimento das } \\
\text { normas da qualidade e } \\
\text { sobre a forma correta } \\
\text { de aplicá-las. } \\
\text { Comunicar-se com as } \\
\text { pessoas, na } \\
\text { organização, de modo } \\
\text { adequado aos seus } \\
\text { contextos de ação. }\end{array}$ \\
\hline 7 & $\begin{array}{l}\text { Exigência por } \\
\text { organização e } \\
\text { documento e } \\
\text { documentação do } \\
\text { trabalho executado. }\end{array}$ & $\begin{array}{l}\text { Centralizar a } \\
\text { resolução de } \\
\text { problemas e a tomada } \\
\text { de decisões. }\end{array}$ & $\begin{array}{l}\text { Possuía o hábito de } \\
\text { tomar para si a } \\
\text { responsabilidade por } \\
\text { quaisquer ocorrências } \\
\text { em sua área de } \\
\text { trabalho, o que, além } \\
\text { de gerar uma carga } \\
\text { elevada de trabalho, } \\
\text { colaborava para a } \\
\text { realização das tarefas } \\
\text { de modo } \\
\text { desorganizado e } \\
\text { muito informal. }\end{array}$ & $\begin{array}{l}\text { Atitude de } \\
\text { autocontrole e de } \\
\text { questionamento ante o } \\
\text { surgimento de } \\
\text { problemas e de novas } \\
\text { demandas no } \\
\text { trabalho. } \\
\text { Saber delegar a } \\
\text { realização de tarefas e } \\
\text { a solução de } \\
\text { problemas. }\end{array}$ \\
\hline 8 & $\begin{array}{l}\text { Ênfase sobre a } \\
\text { organização e limpeza } \\
\text { do ambiente de } \\
\text { trabalho, e maior } \\
\text { preocupação com a } \\
\text { qualidade do produto } \\
\text { final. } \\
\text { Aumento da carga de }\end{array}$ & $\begin{array}{l}\text { Na visão do } \\
\text { supervisor, não foi } \\
\text { preciso desaprender. }\end{array}$ & $\begin{array}{l}\text { (Não houve } \\
\text { desaprendizagem). }\end{array}$ & $\begin{array}{l}\text { Postura de atenção e } \\
\text { responsiva em relação } \\
\text { às necessidades do } \\
\text { cliente. } \\
\text { Operação do sistema } \\
\text { informatização de } \\
\text { gestão da produção. }\end{array}$ \\
\hline
\end{tabular}


\begin{tabular}{|l|l|l|}
\hline & trabalho. & \\
\hline Fonte: elaborado pelos autores, com base nos resultados da pesquisa (2016).
\end{tabular}

Tais resultados, provindos da análise da relação da aquisição de novas competências com a desaprendizagem, permitem sugerir que, ao contrário das abordagens em que a desaprendizagem é apontada como um processo linear e automatizado de abandono deliberado ou esquecimento intencional de antigos aprendizados (CEPEDA-CARRIÓN et al., 2011; TSANG; ZAHRA, 2008), o desaprendizado dos supervisores sinalizou uma ação reflexiva, importante para a ressignificação do trabalho e entendimento das novas competências, necessárias à execução de seu trabalho (SANDBERG; DALL'ALBA, 2006; ZARIFIAN, 2001). Esta perspectiva é consoante a de Becker (2005), segundo a qual a sustentação das mudanças na organização passa por abrir mão de antigos hábitos, algumas vezes, ao mesmo tempo em que as novas práticas e procedimentos são aprendidos. Na visão de Becker (2010), em um contexto organizacional, a prática de antigos aprendizados é abandonada mediante o entendimento de que a mudança é importante para a organização e pela avaliação individual de que o novo caminho representa uma situação melhor que a anterior.

Outro aspecto relevante, sobre a relação entre a desaprendizagem e o desenvolvimento de competências, trata-se do entendimento de que a desaprendizagem, em especial, a de conhecimentos técnico-funcionais não significa a perda destes, como explicita um dos supervisores:

No caso, o que eu sabia, eu, apenas, deixei ali. Está aqui, está guardado, está no meu conhecimento, tudo que eu sabia até ali, porém eu não posso aplicar mais hoje. Mas, se chegar uma hora, se necessário, eu tenho no fundo do bauzinho, como se diz, aquele conceito que eu tinha, antigamente. (Supervisor 2)

Tal visão que coaduna com a perspectiva de Le Boterf (2003), de que os saberes são recursos pessoais mobilizados em ações adequadas à situação. No caso dos supervisores, os antigos aprendizados que não são mais aplicados às rotinas de trabalho, em decorrência das mudanças provocadas pela implantação do SGQ, continuam incorporados ao repertório de recursos pessoais do sujeito, para, se necessário, serem acionados em outras situações:

Não é questão de você esquecer aquilo que está gravado, você vai usar sim. Na hora que precisar, basta usar. Você tem que ser meio camaleão, dependendo da situação em que você está. Dependendo da situação em que você se encontra no momento, você precisa usar a arma que você tem, eu acho, no momento certo. Esse aprendizado que você tem você vai usando ele e vai se adequando às situações. (Supervisor 8)

Como salientam Hislop et al. (2014), a desaprendizagem não se traduz na extinção ou perda de aprendizados prévios, pois, se desaprender trata-se de uma ação deliberada que tem 
por finalidade interromper o uso de um antigo aprendizado, tal conteúdo poderá ser acionado novamente pela pessoa e aplicado em situações futuras. Desse modo, pela perspectiva do desenvolvimento de competências, é possível apreender que a desaprendizagem mostra-se menos como o simples descarte de antigos aprendizados e mais como um processo em que os aprendizados já adquiridos são acionados de acordo com a exigência da situação enfrentada pelo indivíduo.

\section{Considerações finais}

Por meio deste estudo, buscou-se compreender como o desenvolvimento de novas competências individuais relaciona-se com a desaprendizagem, dadas as considerações quanto à escassez de evidências empíricas sobre a relação entre a desaprendizagem e a aquisição de novas aprendizagens. Os resultados, circunscritos às experiências vivenciadas e relatadas pelos sujeitos, indicam que a desaprendizagem - compreendida como a adoção de um comportamento voltado à interrupção da prática de aprendizados antigos - favoreceu a adoção de uma postura crítica e de questionamento em relação às atividades desempenhadas, o que, por sua vez, representa um elemento essencial para a formulação de novas compreensões sobre o próprio trabalho e à aquisição das competências demandadas pelo contexto em que a pessoa está inserida.

Avalia-se que a desaprendizagem em seu nível individual mostra-se mais como um elemento que facilita a adoção de uma atitude de reflexão e menos como um processo de abandono ou descarte de aprendizados. Por essa perspectiva, julga-se que a relevância da desaprendizagem para a aquisição de novos aprendizados e o aprimoramento das competências decorre não do quanto os antigos conhecimentos podem bloquear novas aprendizagens, mas, em especial, da compreensão sobre como a desaprendizagem pode facilitar a ressignificação de antigos conhecimentos e comportamentos.

Nessa linha, ganha relevo o entendimento, expresso pelos sujeitos da pesquisa, de que o desaprendizado de conhecimentos ou saberes técnicos não significa, necessariamente, a perda destes. Ao contrário, tais aprendizados prévios, uma vez considerados úteis em outros contextos, podem ser mantidos pelo indivíduo e, se necessário, aplicados às situações de trabalho, de modo similar ao que ocorre com as competências transferíveis. Assim, pela perspectiva do desenvolvimento de competências, entende-se que a desaprendizagem não deva ser tomada como o oposto da aprendizagem, mas, sim, como um elemento facilitador da 
tomada de consciência quanto à premência de modificar o comportamento, especialmente, nas situações em que há baixa predisposição ou prontidão das pessoas para a aquisição e a prática de novos aprendizados.

Em relação aos resultados atinentes às competências desenvolvidas pelos sujeitos da pesquisa, julga-se que as competências informadas pelos supervisores contribuíram para o estabelecimento da nova lógica organizacional buscada pela empresa, baseada nas premissas do SGQ. Não obstante, salienta-se a ausência, nos relatos dos supervisores, de competências importantes à consecução dos demais resultados esperados, como a conquista de novos clientes e de mercados consumidores, em decorrência do que se considera necessário que a organização promova ações voltadas à aquisição de competências mercadológicas e estratégicas, em seus níveis individual e organizacional.

Como prática instituída, o desenvolvimento de competências é vista como um meio para o estabelecimento de um contexto propício para o sujeito agir com iniciativa e responsabilidade perante as situações não previstas (ZARIFIAN, 2001). Contudo o processo de implantação do SGQ colaborou para a formação de um entendimento oposto por parte dos supervisores, segundo o qual o trabalho desempenhado ganhou o significado de uma atividade burocrática e com pouco espaço para que as pessoas ajam de modo não prescrito. Assim, no sentido de evitar a eventual cristalização destas características, no ambiente da organização, mostra-se útil levar em conta a proposição de Sandberg e Dall'Alba (2006), de que o aprimoramento das competências baseia-se em um processo cíclico de questionamento sobre as formas pelas quais o trabalho é concebido. Isto representa que os gestores da empresa podem instituir mecanismos organizacionais que favoreçam a assimilação e a prática cotidiana, pelas pessoas, da reflexão sobre o próprio trabalho e seus desafios.

Como implicações, os resultados desta pesquisa sugerem que a consideração do fenômeno da desaprendizagem, nas investigações sobre o desenvolvimento de competências, pode contribuir para o aprofundamento da compreensão dos elementos que tomam parte no processo de conscientização pessoal sobre a necessidade de promover mudanças na forma de pensar e de agir em relação ao trabalho desempenhado e de busca pelas aprendizagens tidas como importantes. Também, os achados permitem reforçar o entendimento segundo o qual a desaprendizagem apresenta-se como um elemento que propicia a alteração de compreensões previamente assimiladas, em contraponto às abordagens teóricas que definem o fenômeno 
como o descarte ou esquecimento de aprendizados antigos (CEPEDA-CARRIÓN et al., 2011; HEDBERG, 1981).

Por último, destaca-se que este estudo possui, como principal limitação, a impossibilidade de generalização de seus resultados, tanto em decorrência de a discussão ter sido feita a partir dos dados coletados por meio de uma fonte, apenas, quanto pela seleção por conveniência dos sujeitos, os quais, desse modo, não são representativos de qualquer população de gestores.

$\overline{1}$ MELTON, A. W.; IRWIN, J. The influence of degree of interpolated learning on retroactive inhibition and the overt transfer of specific responses. American Journal of Psychology, v. 53, p. 173-203, 1940. 


\section{REFERÊNCIAS}

AKGÜN, A. E.; BYRNE, J. C.; LYNN, G. S.; KESKIN, H. Learning process in new product development teams and effects on product success: a socio-cognitive perspective. Journal of Engineering \& Technology Management, v. 24, n. 3, p.203-230, 2007.

BROOK, C.; PEDLER, M.; ABBOTT, C.; BURGOYNE, J.; On stopping doing those things that are not getting us to where we want to be: Unlearning, wicked problems and critical action learning. Human Relations, v. 69, n. 2, 369-389, 2016.

BADDELEY, A.; EYSENCK, M. W.; ANDERSON, M. C. Memória. Tradução Cornélia Stolting. Porto Alegre: Artmed, 2011.

BAUER, M. W. Análise de conteúdo clássica: uma revisão. In: BAUER, M. W.; GASKELL, G. Pesquisa qualitativa com texto, imagem e som: um manual prático. Petrópolis: Vozes, 2002.

BECKER, K. L. Individual and organisational unlearning: directions for future research. International Journal of Organisational Behaviour, v. 9, n.7, p. 659-670, 2005.

BECKER, K. Facilitating unlearning during implementation of new technology. Journal of Organizational Change Management, v. 23, n. 3, p. 251-268, 2010.

BECKER, K.; HYLAND, P.; ACUTT, B. Considering unlearning in HRD practices: an Australian study. Journal of European Industrial Training, v. 30, n. 8, p. 608-621, 2006.

BOYATZIS, R. The competent manager: a model for effective performance. New York: Wiley, 1982.

CEGARRA-NAVARRO, J. G.; ELDRIDGE, S.; WENSLEY, A. K. P. Counter-knowledge and realised absorptive capacity. European Management Journal, v. 32, p. 165-176, 2014.

BRYMAN, A. Social research methods. 3. ed. Oxford: Oxford University Press, 2004.

CRESWELL, J. W. Projeto de pesquisa: métodos qualitativo, quantitativo e misto. 2. ed. Porto Alegre: Artmed, 2007.

CEPEDA-CARRIÓN， G.; CEGARRA-NAVARRO， J. G.; MARTÍNEZ-CARO, E.; ELDRIDGE, S. How can managers in the hospital in the home units help to balance technology and physician-patient knowledge? International Journal for Quality in Health Care, v. 23, n. 5, p. 600-609, 2011.

CHEETHAM, G.; CHIVERS, G. The reflective (and competent) practitioner: a model of professional competence which seeks to harmonise the reflective practitioner and competence-based approaches. Journal of European Industrial Training, v. 22, n. 7, p. 267-276, 1998.

CHEETHAM, G.; CHIVERS, G. A new look at competent professional practice. Journal of European Industrial Training, v. 24, n. 7, p. 374-383, 2000.

FELDMAN, M. S.; PENTLAND, B. T. Reconceptualizing organizational routines as a source of flebility and change. Administrative Science Quartely, v. 48, p. 94-118, 2003.

GEPHART, R. Paradigms and research methods. Research Methods Division Forum, v. 4, 1999.

GUBA, E. G.; LINCOLN, Y. S. Competing paradigms in qualitative research. In: DENZIN, N. K.; LINCOLN, Y. S. Handbook of qualitative research. SAGE Publications, 1994.

HEDBERG, B. How organizations learn and unlearn. In: NYSTROM, P. C.; STARBUCK, W. H. (Org.) Handbook of organizational design, v. 1, Oxford: Oxford University Press, 1981.

HISLOP, D.; BOSLEY, S.; COOMBS, C. R.; HOLLAND, J. The process of individual unlearning: a neglected topic in an under-researched field. Management Learning, v. 45, n. 5, p. 540-560, 2014. 
ILLERIS, K. How we learn: learning and non-learning in school and beyond. New York: Routledge, 2009.

LE BOTERF, G. Desenvolvendo a competência dos profissionais. Porto Alegre: Artmed, 2003.

LE DEIST, F. D.; WINTERTON, J. What is competence? Human Resource Development International, v. 8, n. 1, p. 27-46. 2005.

LEE, L. T. S. The effects of challenge and hindrance stressors on unlearning and NPD success: The moderating role of team conflict. African Journal of Business Management, v. 5, n. 5, p. 1843-1856, 2011.

LEFRANÇOIS, G. R. Teorias da aprendizagem. São Paulo: Cengage Learning, 2013.

LONGENECKER, C. O.; NEUBERT, M. J.; FINK, L. S. Causes and consequences of managerial failure in rapidly changing organizations. Business Horizons, v. 50, p. 145-155, 2007.

MACDONALD, G. Transformative unlearning: safety, discernment and communities of learning. Nursing Inquiry, v. 9, n. 3, p. 170-178, 2002.

McCLELLAND, D. C. Testing for competence rather than for intelligence. American Psychologist, p. 1-14, Jan. 1973.

MARTIN DE HOLAN, P.; PHILLIPS, N. Organizational forgetting. In: EASTERBYSMITH, M.;LYLES, M.(Orgs.) Handbook of organizational learning and knowledge management. 2. ed. West Sussex: Wiley, 2011. p. 433-451.

MERRIAM, S. B. Qualitative research in practice. Examples for discussion and analysis. San Francisco: Jossey-Bass, 2002.

NAVARRO, J. G. C.; RODRIGO-MOYA, B. Desaprendizaje individual: un paso previo a la creación del capital relacional. Cuadernos de Administración, v. 17, n. 27, p. 11-32, 2004.

PARRY, S. B. The quest for competencies, Training, p. 48-56, July. 1996.

POSTMAN, L.; UNDERWOOD, B. J. Critical issues in interference theory. Memory and Cognition, v. 1, p. 19-40, 1973.

RUSHMER, R.; DAVIES, H. T. O. Unlearning in health care. Quality and Safe in Health Care, v. 13, n. 2, p. 10-15, 2004.

SANDBERG, J. Understanding human competence at work: an interpretative approach. Academy of Management Journal, v. 43, n. 1, p. 9-25, 2000.

SANDBERG, J; DALL'ALBA, G. Reframing competence development at work. In: Castleton, G., Gerber, R.; Pillay, H. (Orgs.) Improving Workplace Learning. Nova Publishers: New York, 2006.

SPENCER, L. M.; SPENCER, S. M. Competence at work: models for superior performance. New York: John Wiley \& Sons, 1993.

TSANG, E. W. K.; ZAHRA, S. A. Organizational unlearning. Human Relations. v.61, n.10, p. 1435-1462, 2008.

VELDE, C. An alternative conception of competence: implications for vocational education. Journal of Vocational Education \& Training, v. 51, n. 3 p. 437-447, 1999.

WHITE, R. Motivation reconsidered: the concept of competence. Psychological Review, v. 66, p. 279-333, 1959.

ZARIFIAN, P. Objetivo competência: por uma nova lógica. São Paulo: Atlas, 2001. 